\title{
A comparative study of the kinetics and isotherm of adsorption of a cationic dye by different natural wastes
}

\author{
Meryem Kerrou $^{1, *}$, Najia Bouslamti $^{1}$, Abdelaziz Raada ${ }^{1}$, Abdellah Elanssari $^{1}$, and Driss Mrani \\ Moulay Ismail University, Faculty of Science and Technique, Department of Chemistry, Laboratory of Chemistry, Environment and \\ Materials Analysis team, Errachidia, Morocco
}

\begin{abstract}
In many countries, water pollution from industrial wastewater is a serious problem. This type of pollution can have a harmful impact on the environment, to reduce the effects of these pollutants, several physico-chemical methods are implemented, in particular adsorption on bioadsorbents, it is a common process to remove traces of pollutants from water, the aim of our work is to realize a comparative experimental study of isotherms and adsorption kinetics of methylene blue (MB) on three substrates: sugar cane bagasse (SCB), almond shell (AS) and walnut shell (WS). The results of equilibrium kinetics show that walnut shell (WS) binds better to methylene blue than other substrates. The results also show that the adsorption kinetics are described by the expression of the pseudo-second order model. The isotherms of adsorption of methylene blue (MB) by sugarcane bagasse (SCB), walnut shell (WS) and almond shell are perfectly described by Langmuir's model and that walnut shell adsorbs methylene blue better than other substrates.
\end{abstract}

\section{Introduction}

The wastewater from industrial discharges because of dyes from the industrial textile, cosmetics, printing, dyeing, food dyes and paper manufacturing[1] , it present a danger for us and our environment because of their low biodegradability[2], in addition, some dyes degrade into compounds that have toxic, mutagenic or carcinogenic effects on living organisms [3].

The world production of dyes is estimated by 800,000 t/year and the authors have classified the dyes in two categories according to their chemical constituents taking into consideration the nature of the chromophores that compose them: azo, anthraquinone, triarylmethane and phthalocyanine groups, others researchers have classified them according to the various application technologies: anionic (acid, acid-mordant, direct, reactive, vat, sulfur dyes) or cationic (basic)[4]. Methylene blue is a cationic dye used for dyeing cotton, wood and silk is like a very toxic dye with harmful effects such as vomiting, increased heart rate, diarrhea, shock, cyanosis, jaundice, and quadriplegia[5]. For this reason, it is necessary to treat wastewater containing methylene blue before discharge.

The Adsorption method is considered to be one of the most cost effective technologies, more precisely adsorption on activated carbon remains one of the most efficient treatment techniques, however in the case of some dyes, overdosing of carbon is required for a better efficiency which makes the cost of the operation expensive. morver ,the regeneration of activated carbon is a delicate operation and there is no unanimity on its usefulness[6]. for this reason several researchers have focused of certain adsorbents from naturel waste such as fruit trees, eggshells, palm waste or sawdust, for use Biosorbants with a view to replacing activated carbon[7].

In this context, we proposed to test three substrates: sugarcane bagasse, almond shell and walnut shell, which are easily obtainable and realistic for developing countries and present a very important potential for wastewater treatment[8].The aim of this work is a comparative study based on the adsorption kinetics and isotherms of the three selected substrates.

\section{Materials and Methods}

\subsection{Adsorbat}

The dye chosen for the study of the adsorption capacity of the three adsorbents is methylene blue it is a cationic dye supplied by (Sigmae Aldrich) (99.9\% purity), it was used without any prior purification. Methylene blue has a molecular weight of $319.85 \mathrm{~g} / \mathrm{mol}$, aqueous solutions of methylene blue absorb at wavelengths up to 665 nanometers and with a chemical structure shown in Figure 1.<smiles>CN(C)c1ccc2nc3ccc(N(C)C)cc3[s+]c2c1</smiles>

Fig. 1. The chemical structure of methylene blue (MB)

\footnotetext{
* Corresponding author: kerrou.meryem@gmail.com
} 


\subsection{Adsorbents}

The three adsorbents choose bagasse from sugar cane, almond shell and walnut shell are less expensive lignocellulosic waste and are widely available in Morocco. The sugar cane bagasse was collected from the local abundance after juice extraction for the almond shell and walnut shell were collected at the region of Guir province of Midelt. The preparation of these three substrates is based on three steps:

Washing several times to remove the organic matter, drying in an oven at a temperature of $105^{\circ} \mathrm{C}$ for 24 hours, then grinding and finally sieving to a particle size equal to $250 \mu \mathrm{m}$.

\subsection{Kinetic study}

To study the adsorption kinetics of the dyes at $25^{\circ} \mathrm{C}$, a volume of $50 \mathrm{ml}$ of solution containing the dye of concentration $25 \mathrm{mg} / \mathrm{L}$ is put in contact with an amount of $0.1 \mathrm{~g}$ of adsorbent, at time $\mathrm{t}=0$ in a $0.5 \mathrm{~L}$ beaker, homogenization was carried out in an incubator type (Jisico-model J-NSIL_R) with a stirring speed equal to $127 \mathrm{r} / \mathrm{min}$, the sample is filtered in a Wothman type filtration system with a diameter of $0.45 \mu \mathrm{m}$, the supernatant is immediately determined by a UV-Visible spectrophotometer type (Shimadzu 1601) at a wavelength of maximum absorbance of the WB $($ max $=665 \mathrm{~nm})$.

The quantity of fixed dye per gram of adsorbent is given by the following relation:

$$
Q_{t=} \frac{\left(C_{0}-C_{t}\right) * V}{m}
$$

With : $\mathrm{Q}_{\mathrm{t}}$ (mg.g-1) is the quantity adsorbed at time $\mathrm{t}$ (min), $\mathrm{C}_{0}$ and $\mathrm{Ct}(\mathrm{mg} . \mathrm{L}-1)$ are the initial concentration and the concentration at time $t$ in dye, $\mathrm{V}(\mathrm{L})$ is the volume of the solution and $\mathrm{m}(\mathrm{g})$ is the quantity of the adsorbent in solution.

The use of kinetic equations in dye sorption has been studied for many years. Lagergren proposed a pseudofirst-order equation for sorption of a liquid/solid system based on solid capacity. The Lagergren equation is the most widely used equation in liquid sorption and can be represented as follows[9]:

$$
\ln \left(q_{e}-q_{t}\right)=\ln q_{e}-K_{1} \mathrm{t}
$$

The kinetic equation of the pseudo-second order was proposed by Blanchard et al. is expressed as follows[10] :

$$
t / q_{t}=\frac{1}{K_{2} \times q^{2}}+\frac{t}{q_{e}}
$$

With:

qe: equilibrium amount of adsorbate per gram of adsorbent $(\mathrm{mg} / \mathrm{g}), \mathrm{t}$ : contact time $(\mathrm{min}), \mathrm{K}_{1}$ and $\mathrm{K}_{2}$ : velocity constant for the first order respectively (min-1), the pseudo-second order (g .min/mg).

\subsection{Adsorption isotherm}

The last step is the modeling of adsorption equilibria which consists in representing by mathematical laws, the relation to the equilibrium between the quantity of pollutant in liquid phase $(\mathrm{Ce})$ and that adsorbed on the material (Qe) [11] this study is analyzed by the application of Langmuir's model and Freundlich's model, which are classical and simple models.

Langmuir's model is based on the following assumptions:

The formation of a single layer of adsorbate on the surface of the adsorbent, the existence of adsorption sites and the surface is uniform with no interaction between the adsorbed molecules [2]. Langmuir's equation as follows:

$$
q_{e}=\frac{K_{e} q_{m} C_{e}}{1+K_{L} C_{e}}
$$

Where $\mathrm{q}_{\mathrm{e}}$ and $\mathrm{q}_{\mathrm{m}}(\mathrm{mg} / \mathrm{g})$ are the amount adsorbed at equilibrium and the maximum amount adsorbed at saturation of the monolayer, $\mathrm{Ce}(\mathrm{mg} / \mathrm{L})$ is the equilibrium concentration and $\mathrm{K}_{\mathrm{L}}(\mathrm{L} / \mathrm{mg})$ is Langmuir's constant.

The Freundlich model proposes a heterogeneity of the adsorption surface with sites of different adsorption energies, the model is described by the following equation [12]:

$$
q_{e}=K_{F} C_{e}^{1 / n}
$$

Where qe $(\mathrm{mg} / \mathrm{g})$ is the equilibrium amount adsorbed, KF and $\mathrm{n}$ are Freundlich's constants and $\mathrm{Ce}(\mathrm{mg} / \mathrm{L})$ is the equilibrium concentration of the solute.

\section{Results and discussions}

\subsection{Adsorption kinetics of MB by different substrates}

Figure 1 shows the evolution of the quantity absorbed as a function of contact time. MB adsorption kinetics on sugarcane bagasse, almond shell and walnut shell show the same patterns with a high MB adsorption capacity on the substrates during the first minutes. This can be explained by the presence of a large number of active sites on the adsorbents [13] and then it becomes slower and slower until the equilibrium state. The equilibrium time is established after $20 \mathrm{~min}$ for the studied adsorbents. In the equilibrium state almond shell fixes MB better than sugarcane bagasse and walnut shell with a maximum adsorption amount equal to $11.244 \mathrm{mg} / \mathrm{L}$. From the results in Table 1 it can be seen that the pseudo-second order model perfectly describes the adsorption kinetics of BM by the biosorbents with a correlation coefficient equal to 0.99 , and the calculated values of the adsorbed quantity at equilibrium qe,cal are very close to the experimental values qe,exp for the three biadsorabants studied.

\subsection{Adsorption equilibrium}

The isotherm of MB adsorption by SCB, AS and WS was measured at $25^{\circ} \mathrm{C}$, the adsorbate-adsorbent contact time was set at $1 \mathrm{~h}$ and was chosen on the basis of the results of MB adsorption kinetics by the Biosorbents used, According to figure 4 we notice that the isotherms of 
adsorption of MB by the SCB, AS, WS show the same paces and are type L curves according to the Giles classification. This type of isotherm means that adsorption becomes more and more difficult with the increase of the concentration following a decrease of the active adsorption sites. Figures 5 and 6 present the results of the modeling test of the isotherms of adsorption of MB by $\mathrm{SCB}$, AS and WS. According to the correlation coefficients presented in Table 2, we can see that the isotherms of adsorption are described perfectly with the Langmuir and Freundlich models.

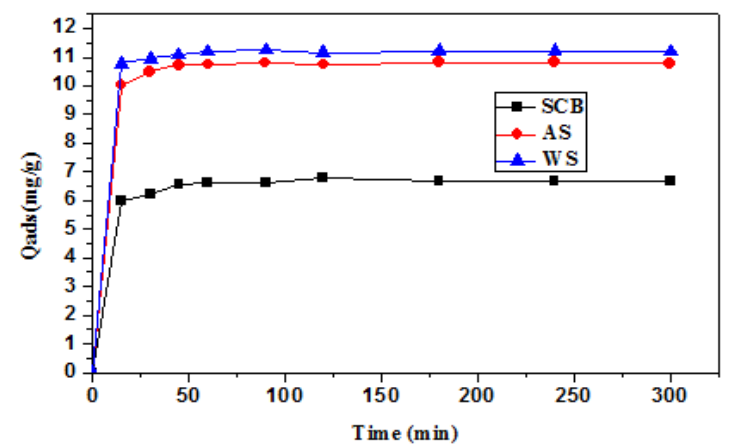

Fig. 1. Adsorption kinetics of $M B$ on the bioadsorbents used.

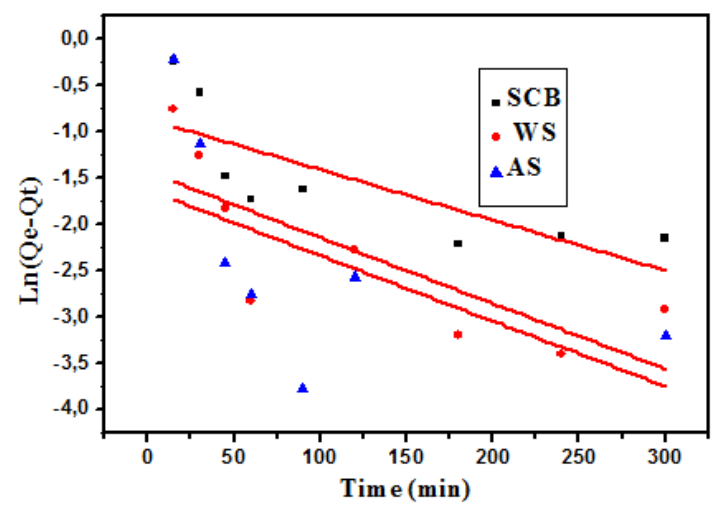

Fig. 2. Simulation of MB adsorption kinetics by the pseudo first order model

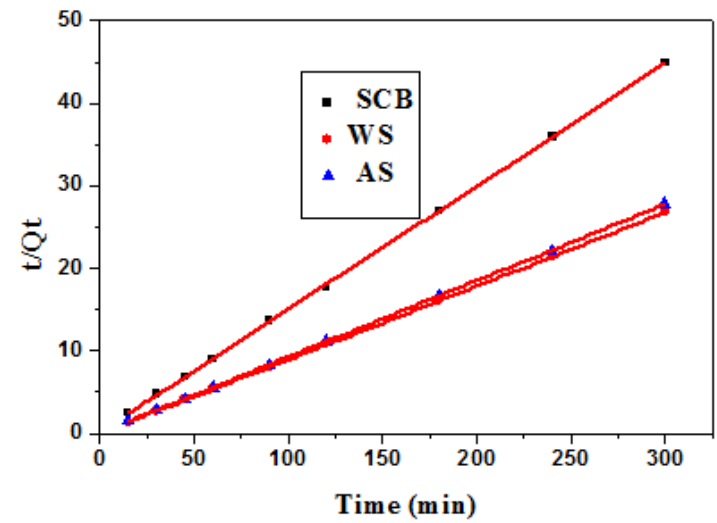

Fig. 3. Simulation of MB adsorption kinetics by the pseudo second order model
Table 1. Kinetic parameters related to the adsorption of BM on the bioadsorbents used

\begin{tabular}{|c|c|c|c|c|}
\cline { 2 - 5 } \multicolumn{1}{c|}{} & Biosorbants & $\begin{array}{c}\text { Sugracane } \\
\text { bagasse } \\
\text { (SCB) }\end{array}$ & $\begin{array}{c}\text { Almond } \\
\text { Shell } \\
\text { (AS) }\end{array}$ & $\begin{array}{c}\text { Walnu } \\
\text { t Shell } \\
\text { (WS) }\end{array}$ \\
\cline { 2 - 5 } & $\begin{array}{c}q_{e, \text { exp }} \\
(\mathrm{mg} / \mathrm{g})\end{array}$ & 6,679 & 10,8173 & 11,244 \\
\hline \multirow{2}{*}{$\begin{array}{c}\text { Pseudo } \\
\text { first- } \\
\text { order } \\
\text { model }\end{array}$} & $\mathrm{k}_{1}\left(\mathrm{~min}^{-1}\right)$ & 0,0055 & 0,0071 & 0,0071 \\
\cline { 2 - 5 } & $q_{e, \text { cal }}(\mathrm{mg} / \mathrm{g})$ & 0,424 & 0,197 & 0,24 \\
\cline { 2 - 5 } & $\mathrm{R}^{2}$ & 0,6182 & 0,3198 & 0,6187 \\
\hline \multirow{3}{*}{$\begin{array}{c}\text { Pseudo } \\
\text { second } \\
\text { order } \\
\text { model }\end{array}$} & $\begin{array}{c}\mathrm{k}_{2}(\mathrm{~g} \cdot \mathrm{mg}- \\
\left.1 . \mathrm{min}^{-1}\right)\end{array}$ & 0,123 & 0,142 & 0,204 \\
\cline { 2 - 5 } & $q_{e, \text { cal }}(\mathrm{mg} / \mathrm{g})$ & 6,72 & 10,822 & 11,22 \\
\cline { 2 - 5 } & $\mathrm{R}^{2}$ & 0,99 & 1 & 1 \\
\hline
\end{tabular}

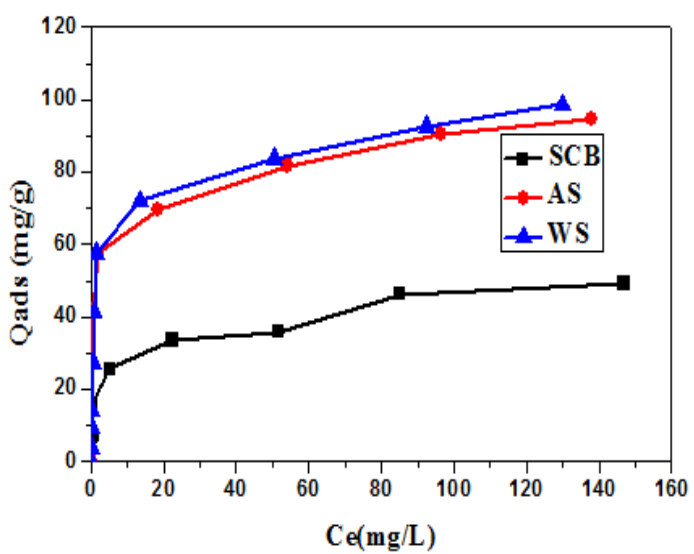

Fig. 4. Isotherm of adsorption of $\mathrm{MB}$ by $\mathrm{SCB}, \mathrm{AS}$ and WS

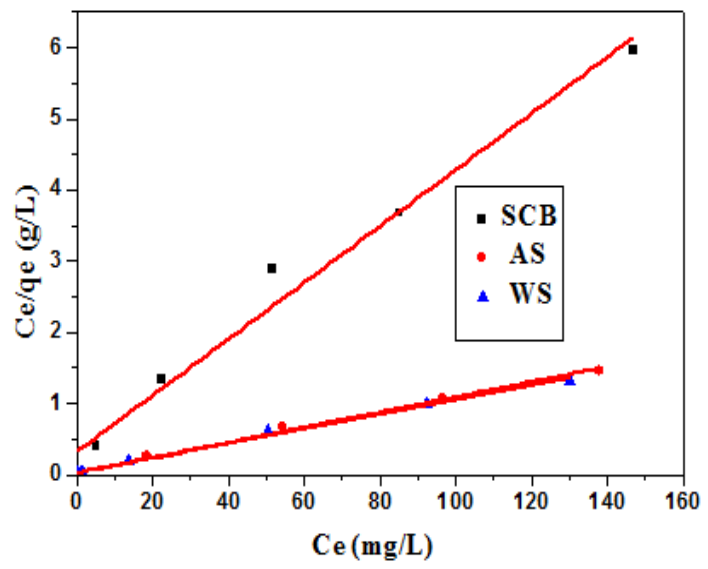

Fig. 5. Simulation of BM adsorption isotherms by the Langmuir model 


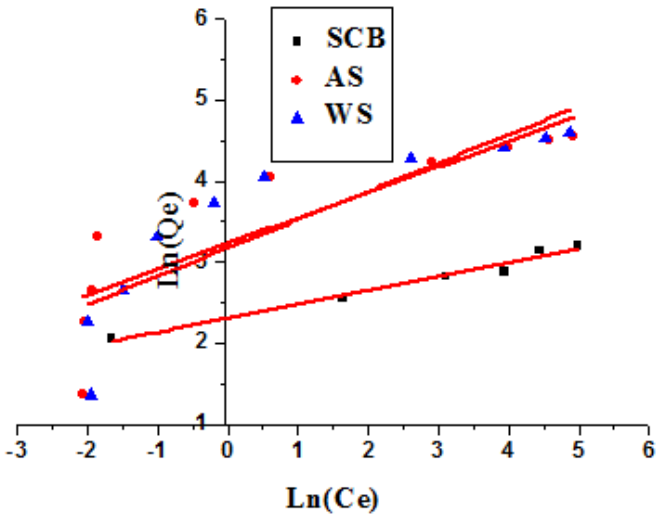

Fig. 6. Simulation of MB adsorption isotherms by the Freundlich model

Table 2. Langmuir and Freundlich model constants of the MB adsorption isotherms by SCB, WS, AS.

\begin{tabular}{|c|c|c|c|c|}
\hline & $\begin{array}{c}\text { Biosorbent } \\
\text { s }\end{array}$ & $\begin{array}{c}\text { Sugracan } \\
\text { e bagasse } \\
(\mathrm{SCB})\end{array}$ & $\begin{array}{c}\text { Almon } \\
\text { d Shell } \\
\text { (AS) }\end{array}$ & $\begin{array}{r}\text { Walnu } \\
\text { t Shell } \\
\text { (WS) }\end{array}$ \\
\hline \multirow{4}{*}{$\begin{array}{c}\text { Langmuir } \\
\text { Model }\end{array}$} & $\mathrm{K}_{\mathrm{L}}(\mathrm{L} / \mathrm{g})$ & 0,1224 & 0,412 & 0,391 \\
\hline & $q_{\max }(\mathrm{mg} / \mathrm{g}$ & 25,25 & 94,33 & 97,087 \\
\hline & $\mathrm{R}_{\mathrm{L}}$ & 0,246 & 0,088 & 0,098 \\
\hline & $\mathrm{R}^{2}$ & 0,98 & 0,99 & 0,99 \\
\hline \multirow{3}{*}{$\begin{array}{c}\text { Freundlic } \\
\text { h Model }\end{array}$} & $\mathrm{K}_{\mathrm{F}}$ & 10,0071 & 25,39 & 23,98 \\
\hline & $1 / n$ & 0,172 & 0,3149 & $\begin{array}{c}0, \\
3493\end{array}$ \\
\hline & $\mathrm{R}^{2}$ & 0,97 & 0,72 & 0,76 \\
\hline
\end{tabular}

\section{Conclusion}

The purpose of this article is to achieve a comparative study of isotherms and adsorption kinetics of methylene blue (MB) on three substrates: sugar cane bagasse (SCB), almond shell (AS) and walnut shell (WS). The results show that the adsorption of methylene blue by sugarcane bagasse, almond shell and walnut shell is fast. The experiments also show that the adsorption capacity of MB by walnut shell is higher than that of sugarcane bagasse and almond shell. The MB adsorption kinetics on the three substrates are of the same order (pseudo-second order) with a correlation coefficient equal to 0.99 for SCB, 1 for $\mathrm{AS}$ and $\mathrm{WS}$, the isotherms of $\mathrm{BM}$ adsorption by $\mathrm{SCB}, \mathrm{WS}, \mathrm{AS}$ are perfectly described by the Langmuir model with correlation coefficients equal to $0.98,0.99$ and 0.99 respectively .

\section{References}

1. Ahmad, A., Rafatullah, M., Sulaiman, O., Ibrahim, M.H., Hashim, R.: Scavenging behaviour of meranti sawdust in the removal of methylene blue from aqueous solution. J. Hazard. Mater. 170, 357-365 (2009). https://doi.org/10.1016/j.jhazmat.2009.04.087.

2. Benguella, B., Yacouta-Nour, A.: Elimination des colorants acides en solution aqueuse par la bentonite et le kaolin. Comptes Rendus Chim. 12, 762-771 (2009). https://doi.org/10.1016/j.crci.2008.11.008.

3. Zhang, W., Yan, H., Li, H., Jiang, Z., Dong, L., Kan, X., Yang, H., Li, A., Cheng, R.: Removal of dyes from aqueous solutions by straw based adsorbents: Batch and column studies. Chem. Eng. J. 168, 11201127 https://doi.org/10.1016/j.cej.2011.01.094.

(2011).

4. Mansour, H.B., Boughzala, O., Dridi, dorra, Barillier, D., Chekir-Ghedira, L., Mosrati, R.: Les colorants textiles sources de contamination de l'eau : CRIBLAGE de la toxicité et des méthodes de traitement. Rev. Sci. Eau. 24, 209 (2011). https://doi.org/10.7202/1006453ar.

5. Li, Y., Du, Q., Liu, T., Peng, X., Wang, J., Sun, J., Wang, Y., Wu, S., Wang, Z., Xia, Y., Xia, L.: Comparative study of methylene blue dye adsorption onto activated carbon, graphene oxide, and carbon nanotubes. Chem. Eng. Res. Des. 91, 361-368 (2013). https://doi.org/10.1016/j.cherd.2012.07.007.

6. Sakr, F., Sennaoui, A., Elouardi, M., Tamimi, M., Assabbane, A.: Étude de l'adsorption du Bleu de Méthylène sur un biomatériau à base de Cactus (Adsorption study of Methylene Blue on biomaterial using cactus). J. Mater. Environ. Sci. 6, 397-406 (2015).

7. STONES, A.D.: ETUDE DE L'ADSORPTION DU BLEU DE METHYLENE (BM) A PARTIR DES SOLUTIONS AQUEUSES SUR UN BIOSORBANT PREPARE A PARTIR DES NOYAUX DE DATTE ALGERIENNE. Larhyss J. 135-148 (2016).

8. Chen, H., Zhao, J., Dai, G.: Silkworm exuviae-A new non-conventional and low-cost adsorbent for removal of methylene blue from aqueous solutions. J. Hazard. Mater. 186, 1320-1327 (2011). https://doi.org/10.1016/j.jhazmat.2010.12.006.

9. Wong, Y.C., Szeto, Y.S., Cheung, W.H., McKay, G.: Pseudo-first-order kinetic studies of the sorption of acid dyes onto chitosan. J. Appl. Polym. Sci. 92, 1633-1645 (2004).

10. Chowdhury, S., Saha, P.: Adsorption Kinetic Modeling of Safranin onto Rice Husk Biomatrix Using Pseudo-first- and Pseudo-second-order Kinetic Models: Comparison of Linear and Non-linear 
Methods. CLEAN - Soil Air Water. 39, 274-282 (2011). https://doi.org/10.1002/clen.201000170.

11. Fayoud, N., Younssi, S.A., Tahiri, S., Albizane, A.: Etude cinétique et thermodynamique de l'adsorption de bleu de méthylène sur les cendres de bois (Kinetic and thermodynamic study of the adsorption of methylene blue on wood ashes). J Mater Env. Sci. 11, 3295-3306 (2015).

12. Boumchita, S., Lahrichi, A., Benjelloun, Y., Lairini, S., Nenov, V., Zerrouq, F.: Elimination d'un colorant cationique dans une solution aqueuse par un déchet alimentaire: Epluchure de pomme de terre [Removal of cationic dye from aqueous solution by a food waste: Potato peel].

13. ABOUA, K.N., SORO, D.B., DIARRA, M., DIBI, K., N'GUETTIA, K.R., TRAORE, K.S.: Étude de l'adsorption du colorant orange de méthyle sur charbons actifs en milieu aqueux: influence de la concentration de l'agent chimique d'activation. Afr. Sci. 14, 322-331 (2018). 